\title{
Ecstasy use and depression: A 4-year longitudinal study among an Australian general community sample
}

\author{
Amanda M. George \\ Centre for Applied Psychology, University of Canberra, ACT, Australia, 2601. \\ Ph: +61262012134 \\ Fax: +61262015357 \\ amanda.george@canberra.edu.au \\ Sarah Olesen \\ Psychiatric Epidemiology and Social Issues Unit, The Australian National University, \\ Canberra, ACT, Australia 0200.
}

Centre for Research on Ageing, Health and Wellbeing, The Australian National

University, Canberra, ACT, Australia 0200.

Robert J Tait

Centre for Mental Health Research, The Australian National University, Canberra, ACT, Australia, 0200.

Centre for Research on Ageing, Health and Wellbeing, The Australian National

University, Canberra, ACT, Australia 0200.

National Drug Research Institute, Curtin University, Perth, WA, Australia, 6008.

\section{ABSTRACT}

Rationale: Longitudinal, population-based studies can better assess the relationship of ecstasy use with depression.

Objectives: We examined whether change in ecstasy use was associated with change in depressive symptoms/probable depression over a 4 year period, among a large Australian sample.

Methods: The Personality and Total Health (PATH) project is a longitudinal general community study of Australians from Canberra and Queanbeyan. Data from the youngest cohort when aged $24-30(\mathrm{~N}=2,128)$ and 4 years later $(\mathrm{N}=1,977)$ was included. The Goldberg depression scale and the Brief Patient Health Questionnaire measured depressive symptoms and probable depression, respectively. Multilevel growth models 
also considered demographics, psychosocial characteristics and other drug use.

Results: Ecstasy use was not associated with long-term depressive symptoms or greater odds of depression. Users had more self-reported depressive symptoms when using ecstasy compared to not using. However, differences between people who had and had not ever used ecstasy largely accounted for this. Other factors were more important in the prediction of depression.

Conclusions: It would be premature to conclude that ecstasy use is not related to the development of long-term depressive symptoms, given the relatively low level of ecstasy and other drug use in this community sample. Results showed that other factors need to be considered when investigating ecstasy use and depression.

Keywords: ecstasy, 3,4-Methylenedioxymethamphetamine (MDMA), depression, mental health, general community sample.

\section{INTRODUCTION}

Despite recent decreases in ecstasy use in Australia (Australian Institute of Health and Welfare 2011), the Oceanic region continues to have the highest annual prevalence of the drug (United Nations Office on Drugs and Crime 2012). Use of 3,4-Methylenedioxymethamphetamine (MDMA) has been associated with damage to the serotonin (5-HT) system in animals (e.g. Mueller et al. 2012) and humans (e.g. Buchert et al. 2004). Unsurprisingly many studies have investigated depression among ecstasy users, with residual symptoms reported (e.g. Curran et al. 2004; Curran and Travill 1997) as well as greater symptoms relative to drug naive and/or polydrug controls (e.g. Morgan et al. 2002; Roiser and Sahakian 2004). However, not all studies have found an effect of ecstasy use with depression symptoms (e.g. Scott et al. 2010; Thomasius et al. 2006). Inconsistencies may reflect the heterogeneity of research methodologies which make it difficult to draw conclusions (Guillot 2007; Rogers et al. 2009).

To date, limitations in the literature have included reliance upon small snowball samples and knowledge of study aims among participants. Additionally, as most ecstasy users also use other drugs (Dunn et al. 2007; Hammersley et al. 1999), whether identified 
effects reflect the acute/residual pharmacological effects of other drugs, particularly cannabis, is also an ongoing issue. Some investigations have determined that poorer mental health among ecstasy users is associated more with other drugs (e.g. Daumann et al. 2004; Durdle et al. 2008; Medina and Shear 2007) with a limited number of studies reporting higher scores among ecstasy users, relative to polydrug controls (see Guillot 2007).

Another issue is the possibility of a somatic symptom bias among ecstasy users (Bedi et al. 2010; Sumnall and Cole 2005). George, Windsor and Rogers (2011) found no specific item endorsement bias among ecstasy users on a measure of psychological distress, consistent with Roiser and Sahakian (2004) where somatic depression symptoms were examined among ecstasy users relative to controls. Although, Bedi and colleagues (2010) found differences for somatic anxiety symptoms. Multiple assessments of symptoms may help to address this potential concern.

In addition, there remains a paucity of longitudinal investigations meaning that cause and effect associations cannot be inferred (Rogers et al. 2009). Of the limited studies, some found no evidence for increased depressive symptoms among ecstasy users (Daumann et al. 2004; Thomasius et al. 2006) including a prospective study of incident users over 2 years (de Win et al. 2007). More recently, a decline in BDI scores over 2 years among both current and former ecstasy users was noted among a larger sample (Falck et al. 2008). Results for mood disorders are also mixed-Martin-Santos et al. (2010) found that ecstasy users had a higher incidence of primary mood disorder over 3 years compared with drug naive and cannabis controls, but Lieb et al. (2002) found mood disorders were more likely to precede, rather than follow, ecstasy/amphetamine use. Again, studies have been subject to methodological issues with most relying on small samples and, limited follow up.

Some potential confounds remain unexplored longitudinally in the ecstasy and depression literature. Recent research highlights the importance of considering demographic and psychosocial characteristics, in addition to other drug use. George et al. (2010) found that ecstasy use was not independently associated with psychological distress and that factors, such as education and employment status and other drug use 
were more important. Scott et al. (2010) reported no relationship of lifetime or recent ecstasy use with mood, but stressful life events, lifetime trauma and other drug use emerged as significant predictors. These studies were cross-sectional and thus consideration of the influence of such factors in a longitudinal investigation of ecstasy use with mental health is needed.

The current study aimed to address several issues within the literature. First, the association of ecstasy use with depression was examined among a large Australian general community, rather than a small purposive sample. Second, participants were followed over 4 years. Third, measures of both symptoms and indicators of major depression were used. Next, the study included measures of psychosocial characteristics, such as lifetime trauma and social support meaning that these potential confounds could also be considered. Finally, given the epidemiological nature of the study design, the focus of the current study regarding ecstasy use was not known to participants and interviewers were blind to ecstasy use status. The specific research questions were as follows:

1. Is a change in ecstasy status (use/non-use) associated with changes in self-reported depressive symptoms and probable depression over a 4 year period?

2. Does any effect of ecstasy use hold with consideration for demographics, psychosocial characteristics and use of other drugs?

\section{METHOD}

\section{Participants}

Participants were from the Personality and Total Health (PATH) Through Life Project, a longitudinal investigation which aims to re-interview three age cohorts (20-24, 40-44 and 60-64 years) every 4 years for 20 years. Originally, participants were randomly drawn from the electoral roll of Canberra and the neighboring region of Queanbeyan in 
Australia. Enrolment to vote is compulsory for Australian citizens aged 18 years and over with very rare exceptions. At Wave 1, there was a 58.6\% response rate for the youngest cohort among those who were contactable.

The current investigation includes data from the youngest cohort at Waves 2 and 3 when ecstasy items were included in PATH and participants were aged 24-30 years and 28-34 years, respectively. Of the 2,404 younger participants who completed Wave 1 interviews, 2,139 completed Wave 2 (89\% retention) and 1,978 completed Wave 3 (82\% retention). A total of 2,128 participants provided ecstasy use data at Wave 2 and 1,977 participants at Wave 3 and were included in the current study.

\section{Procedure}

At Wave 2, Participants completed a questionnaire using a hand-held computer, with a trained interviewer in the room to answer any questions. The advantage of increased confidentiality among respondents was noted in a review of web-based surveys for illicit drug use research (Miller and Sønderlund 2010). At Wave 3, participants completed the study via an online survey. This study was approved by the Australian National University Human Research Ethics Committee.

\section{Questionnaire}

\section{Ecstasy use}

At both waves, participants were asked questions regarding lifetime use of ecstasy (ever used ecstasy [pills, E, eccy, XTC and MDMA]) and use in the past year. If they had used the drug in the prior 12 months they were asked often they currently used ecstasy. Response options were: every day, once a week, about once a month, every few months, once or twice a year, less often and finally, don't currently use. Participants were categorized according to their ecstasy use status across three categories: 'current' use (use every day through to once or twice a year or less often), not current use (former use or reported not currently using the drug when asked how frequently they were currently) or 
ecstasy naive (never tried ecstasy).

Two dichotomous ecstasy use variables were created from this information: (1) current use (1) versus non use (0; including former use and never used) and (2) "ecstasy naive" (1) versus current or past use (0). The former variable was 'time-varying'; that is, could take on either value at Wave 2 or 3 . This variable thus captured changes in ecstasy use. The latter variable was time-invariant; that is, it identified participants who had not used ecstasy at either wave, and took on the same value at both waves of data for the same individual. These two variables were simultaneously included in longitudinal models. The latter controlled for the variability in depression that was due to the (known) lower rates of depression amongst people who have never used illicit drugs. Consequently, the remaining effect of ecstasy use can be interpreted as the association between current ecstasy use and depression over the two waves of data over and above that association due to drug naivety.

\section{Brief Patient Health Questionnaire (BPHQ)}

The Brief Patient Health Questionnaire (BPHQ; Spitzer et al. 1999) was completed. This provides a provisional diagnosis or syndrome: to make a formal diagnosis other causes must be ruled out (e.g. bereavement, history of manic episodes, physical illness, medication, drug use). A dichotomous variable was created comprised of no depression/subsyndromal depression ( $\leq$ two symptoms of the depression scale reported as 'more than half days' including item 1 or 2) versus major/other depression (cutoff score of 10 or more for mild depression and five of the nine depression items reported as 'half days or more' or 'on several days' for the suicidal ideation variable for moderate depression).

\section{Goldberg depression scale}

The Goldberg depression scaled (Goldberg et al. 1988) is comprised of a nine-item scale measuring depressive symptoms. Items assess experience of a particular symptom of depression (e.g. loss of weight, lack of energy) in the prior 4 weeks. Item 
response options were dichotomous (yes/no), providing a range of 0-9 with higher scores indicative of more symptoms.

\section{Covariates}

Binary drug use variables were created to categorize participants at each wave as using/not using cannabis and cigarettes. A binary meth/amphetamine variable was created for ever used meth/amphetamines for non-medical purposes. An error in the skip programming at Wave 3 resulted in those who previously reported prior use of both ecstasy and meth/amphetamines, but no ecstasy use in the last 12 months, not being asked for frequency data on their meth/amphetamines use. A binary alcohol use variable was also created to distinguish hazardous/non-hazardous drinkers at each wave according to responses on the Alcohol Use Disorders Identification Test (AUDIT; Saunders et al. 1993) using the recommended cut-off score of $\geq 8$ to indicate hazardous alcohol consumption (Conigrave et al. 1995). At Wave 3, the question used to assess heavy episodic drinking was revised from 6 or more drinks to 5 or more standard drinks for females and 7 or more for males, as consistent with Australian drinking guidelines at the time of Wave 3 interview (National Health and Medical Research Council 2001).

Socio-demographic variables included sex, marital status (married versus separated/never married/divorced/widowed), employment status (full-time/ part-time versus unemployed/not in the labor force), highest level of education (higher school certificate or less, post-school qualification, tertiary educated) and whether experienced financial problems in the past year (often/sometimes versus no).

Psychosocial measures included in analyses were positive social support from friends (range 0-6) and negative interaction with friends (range 0-9; Schuster et al. 1990), total number of lifetime traumas (as assessed by items from the Composite International Diagnostic Interview (World Health Organisation 1994) and number of adverse childhood events (Wave 1 only; Rosenman and Rodgers 2004).

\section{Statistical procedures}

Multilevel models (MLM; also referred to as 'random coefficient models' and 
'mixed models') were used to investigate the associations between ecstasy use and measures of depression over time. This method was chosen over commonly used population-averaged, regression techniques because MLM can be used to simultaneously model and thus 'separate out' differences in depression between people over time ("Level 2”), as well as within-person changes to depression across occasions of measurement (“Level 1"). Differences between individuals are estimated using 'time-invariant' or 'fixed' effects that do not change across measurement occasions (e.g., "ecstasy naive"). Changes within individuals over time are estimated using time-varying effects; that is, variables that can change value at each occasion of measurement (Singer and Willett 2003; e.g., current ecstasy use). This feature of MLM was considered a priority in the current study given the potentially different associations between depression and the 'types' or groups of people that do or do not ever use ecstasy versus the association between changes in ecstasy use. Another considerable advantage of MLM for longitudinal data is the ability to include all available data from any wave in the model (Kwok et al. 2008); that is, it is not reliant to complete cases or use listwise deletion

MLM also accounts for interdependencies in the data due to similarities (i.e., repeated measures) in the same individuals' responses across waves. Such interdependency is typically accounted for by specifying a random intercept for each person (Level 2) in the sample. This is the method used here.

Linear MLMs were used to examine continuous depression scores over time according to ecstasy use. Logistic MLMs were used to examine the odds of depression status (major/other depression versus no depression/subsyndromal depression) over time. These models were conducted in STATA Version 11.0 with the "xtmixed" and "xtmelogit" programs respectively. These programs use an expectation-maximization (EM) algorithm to produce maximum-likelihood estimates of model parameters.

\section{RESULTS}

\section{Current study sample characteristics}

As demonstrated by Table 1, the majority of participants were employed and this 
was a predominantly educated sample, with $44 \%$ having completed tertiary studies by Wave 2. Participants reported a mean 2.8 depressive symptoms in the prior 4 weeks to interview, with $11 \%$ meeting the criteria for major/other depression. Results for substance use variables demonstrate that while the majority of participants had tried cannabis and around a third had tried ecstasy, substance use in the sample was quite moderate in terms of frequency of use. Less than $10 \%$ used cannabis every month or more and close to $15 \%$ reported being a current ecstasy user at Wave 2, with smaller numbers of users for meth/amphetamine use and a decline in substance use at Wave 3.

\section{Changes in ecstasy use over 4 years}

Table 2 presents a summary of participant numbers by ecstasy use status at each wave. At Wave 3, 30 participants who had not reported ecstasy use at Wave 2 reported trying the drug at an age prior to Wave 2 and these cases were added to the "not current user' group. There appeared to be an overall decline in use across waves. For example, of the 316 current ecstasy users at Wave 2, 46\% $(n=145)$ reported not currently using the drug at Wave 3 and a further 10\% $(\mathrm{n}=32)$ reported a decline in frequency of use from every month or more at Wave 2 to less often at Wave 3. In terms of increases in use over time, 51 participants who were ecstasy naive at Wave 2 reported use by Wave 3 (41 had tried ecstasy between waves and 10 were current users by Wave 3). An additional 34 participants 'not currently using' at Wave 2 reported current ecstasy use 4 years later and 6 participants had increased their use over time (move from infrequent to use of the drug monthly or more).

\section{Ecstasy use and Goldberg depression}

Table 3 shows the results of the MLM for Goldberg depression scores over the two waves. Results for Model 1 showed a decline in depressive symptoms across time for the overall sample. The (time-varying) effect of current ecstasy use was significant indicating that participants had greater depressive symptoms when using compared to not using the drug. However, adjustment for ecstasy naivety (Model 2) reduced the coefficient for current ecstasy use from 0.30 to 0.20 and the variable became 
non-significant. This indicates that the effect of ecstasy use was somewhat attributable to differences between people who have never used ecstasy across the 4 years, specifically, the lower depression levels of participants who never tried this drug.

The inclusion of socio-demographics (Model 3) and psychosocial characteristics (Model 4) produced a small suppressor effect on the current ecstasy use variable (that is, this ecstasy variable became more significant when the variability in depression due to these characteristics was accounted for). The final model (Model 5) included other substance use variables and the effect of current ecstasy use was again non-significant. Results for this final model showed that greater depressive symptoms were associated with being female, experiencing financial problems, less education, being unemployed/not in the labor force, a greater number of lifetime traumas and childhood adversities, more negative support and less positive support from friends and being a current smoker. Perhaps unexpectedly, no other substance use variable (hazardous/harmful alcohol use and use of cannabis or meth/amphetamines, in addition to ecstasy use) was associated with a change in depressive symptoms over time.

For exploratory purposes, we graphed the predicted depression scores from the final model by ecstasy use/non-use using average or modal values on the predictors (Figure 1). As shown, there was a general decline in symptoms across the two waves, with the exception of moving from not using ecstasy to using ecstasy at Wave 3. 


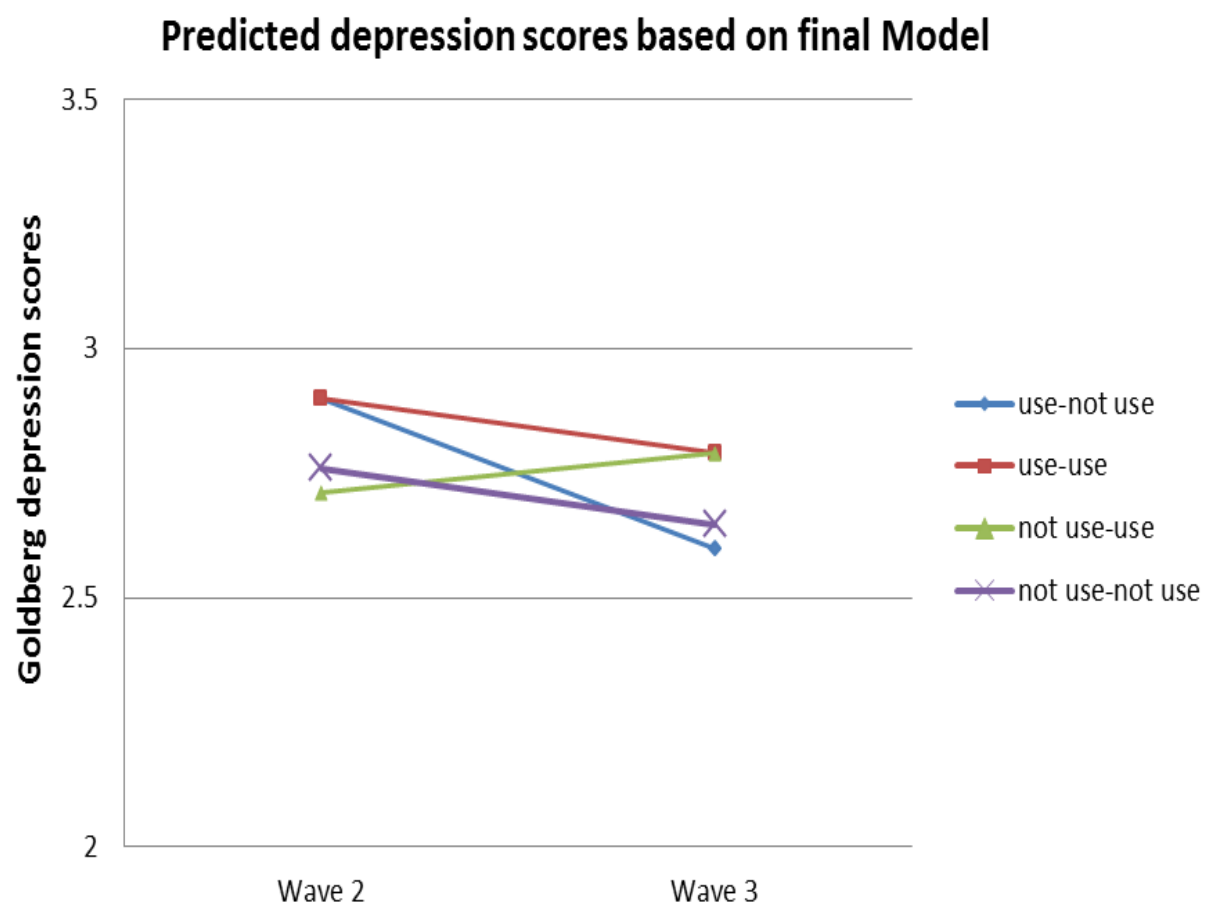

Fig. 1. Predicted Goldberg depression scores based on final MLM by ecstasy use/non-use across the two waves using average/modal predictors.

\section{Ecstasy use and BPHQ}

Table 4 shows the results of the MLM for the odds of major/other depression, as assessed by the BPHQ, over two waves of PATH data. There was no effect of current ecstasy use across waves on the odds of having depression (Model 1) nor were there differences in the odds of depression between ecstasy naive and other participants (Model 2). The final model (Model 5) demonstrated that the odds of having depression were greater when participants were female, unmarried, experiencing financial problems, less education (relative to those who were tertiary educated), unemployed/not in the labor force, had experienced more lifetime traumas and had less positive and more negative interaction with friends. No form of current substance use was associated with the odds of having depression in the final model. 


\section{DISCUSSION}

The current study aimed to determine if change in ecstasy use status was associated with a change in mental health, as assessed by self-reported depressive symptoms and probable depression. Among this general community sample variation in ecstasy use over time was not associated with changes to the odds of having major/other depression, as measured by the BPHQ. Findings demonstrated that participants had more depressive symptoms, as assessed by the Goldberg depression scale, when using the drug compared to not using. However, this was largely accounted for by differences in depression between people who had and had not ever used ecstasy. A general decline in symptoms was noted for the sample across time, with a greater decline in symptoms among those who stopped using the drug compared to those who continued using. Unsurprisingly, given the age of participants, a decline in ecstasy use across the two waves was found.

The consideration of other factors, such as demographics and psychosocial characteristics in the MLM models showed that these variables emerged as more important in the prediction of depressive symptoms and probable depression. Factors associated with higher odds of depression and more depressive measures included experiencing financial problems, unemployment, lower education, more lifetime traumas, more positive and less negative interaction with friends. Of interest, no other substance use variable with the exception of smoking cigarettes for Goldberg depression was significant in the final models. It has previously been reported that smoking is a causal factor in depression (Boden et al. 2010) thereby highlighting the importance of controlling for other factors when examining these associations.

As noted, inclusion of sociodemographic factors, such as education and employment and psychosocial characteristics, such as childhood adversity produced a small suppressor effect on the ecstasy use variable for Goldberg depression. That is, the effect of ecstasy use became more significant with the inclusion of these variables. Interestingly, these variables had little effect on the other illicit drug use variables. This 
may reflect the atypical drug use profile of ecstasy users given that higher employment, more education, support from friends and less childhood adversity/lifetime trauma was associated with fewer depressive symptoms.

Results presented here are broadly consistent with the bulk of research that has examined ecstasy use and depression over time. For example, Falck et al. (2008) reported an overall decline in depressive symptoms over time for both continuous and abstention users and others reported no effect of ecstasy use over time (Daumann et al. 2004; de Win et al. 2007; Thomasius et al. 2006). However, unlike Martin-Santos et al. (2010) where it was found that ecstasy users had a higher incidence of primary mood disorder over a 3 year period, no association of ecstasy use with probable depression was detected here. It is important to note the relatively low level of ecstasy and other drug use in the current community sample which may have contributed to this difference. We did, however, demonstrate an overall decline in symptoms across the sample by ecstasy use/non-use except for those who moved from not using the drug to using at Wave 3. With a heavier using sample the result for ecstasy use may have been significant, despite the identified importance of controlling for other factors.

Similar to other studies (George et al. 2010; Scott et al. 2010) it emerged that other factors were more important in the prediction of depression than ecstasy use. The benefit of considering both demographics and psychosocial characteristics which are often excluded in the literature when examining ecstasy and mental health was apparent. However, unlike these investigations, we did not detect a significant effect of other drug use with the exception of current smoking for Goldberg depression. This finding, particularly for cannabis use, was unexpected. It may again reflect the relatively low level of drug use among the current sample or the inclusion of binary drug use variables in the longitudinal models.

The strengths of the current study include use of a population-based sample as opposed to the typical purposive/snowball samples and examination of participants over 4 years. Additionally, use of multiple measures of depression (both self-report and probable depression) should be noted, as well as the adjustment for other risk factors that may be 
associated with both ecstasy use and mental health. An important contribution is that we showed the effect of current ecstasy use was largely driven by differences between participants who had or had never used the drug. If this had not been considered one could erroneously conclude that it was ecstasy use per se which was linked to changes in depression.

The epidemiological nature of the study makes an important contribution. However, information regarding ecstasy use was limited. Ecstasy dosage was unknown and analyses were limited to current use/non-use of ecstasy and other drugs. The effect of former use was limited by the lack of knowledge regarding former drug use. Those reporting they 'don't currently use' and those who had ever tried the drug, but not used in the prior year, were included in the group of 'not current users'. Unlike most purposive investigations, the current sample had a relatively low level of ecstasy and other drug use. Small samples of ecstasy users were a concern/limitation, and an unavoidable outcome of using community-based samples. We still, however, consider our sampling method to be a significant strength of the study because it addresses this limitation from other studies. Also, the relatively small sample size makes for a 'conservative' estimate (i.e., if anything, the effect is underestimated, rather than inflated, which may be the case in purposively-recruited samples).

It would be premature to conclude that ecstasy use is not related to the development of long-term depressive symptoms, on the basis of findings presented here. It is possible that different results could have been obtained among a heavier using sample. Additionally, early onset of ecstasy use and other risk factors for depression were not examined here. As per other studies among human samples, the purity and presents of adulterants in the ecstasy was unknown. Street 'ecstasy' may contain little or no MDMA and instead maybe a mixture of meth/amphetamines, ketamine and other substances (Australian Crime Commission 2012). The narrow age bracket and geographical distribution of the sample limit generalization of these findings, and alternative indicators of ecstasy use (such as dosage) which were not assessed may have altered results.

Future research should consider other factors, such as psychosocial characteristics 
when examining the effect of ecstasy and other drug use longitudinally. Examining longitudinal effects, particularly among population-based samples, with detailed drug use information should account for differences between people who never use this drug rather than changes in ecstasy use per se. The former effect may confound or be an artefact of these differences. Results presented here are broadly consistent with the existing longitudinal literature which has generally failed to identify a specific effect of ecstasy use on mental health over time. Still, the continual assessment of users/non-users beyond a 4 year period with heavier using samples would also enable the investigation of threshold effects and the possibility of reversal of damage among former users of the drug to be better understood.

\section{Acknowledgements}

We thank Patricia Jacomb, Karen Maxwell, Helen Christensen, Tony Jorm, Bryan Rodgers, Kaarin Anstey and the PATH interviewing team and participants in this study. Funding was provided by the National Health and Medical Research Council (NMHRC) Program Grant (No. 179805) and an Early Career Researchers Grant from the University of Canberra for this study. Robert Tait's position was funded by the Australian National University. 


\section{REFERENCES}

Australian Crime Commission (2012) Illicit Drug Data Report 2010-2011. ACC, Canberra

Australian Institute of Health and Welfare (2011) 2010 National Drug Strategy Household Survey Drug statistics series no 25 Cat no PHE 145. AIHW, Canberra

Bedi G, Van Dam NT, Redman J (2010) Ecstasy (MDMA) and high prevalence psychiatric symptomatology: somatic anxiety symptoms are associated with polydrug, not ecstasy, use. Journal of Psychopharmacology 24: 233-240.

Boden JM, Fergusson DM, Horwood LJ (2010) Cigarette smoking and depression: tests of causal linkages using a longitudinal birth cohort. British Journal of Psychiatry 196.

Buchert R, Thomasius R, Wilke F, Petersen K, Nebeling B, Obrocki J, Schulze O, Schmidt U, Clausen M (2004) A voxel-based PET investigation of the long-term effects of "ecstasy" consumption on brain serotonin transporters. American Journal of Psychiatry 161: 1181-1189.

Cole JC, Michailidou K, Jerome L, Sumnall HR (2006) The effects of stereotype threat on cognitive function in ecstasy users. Journal of Psychopharmacology 20: 518-525.

Conigrave K, Hall W, Saunders JB (1995) The AUDIT questionnaire: choosing a cut-off score. . Addiction 90: 1349-1356.

Curran HV, Rees H, Hoare T, Hoshi R, Bond A (2004) Empathy and aggression: two faces of ecstasy? A study of interpretative cognitive bias and mood change in ecstasy users. Psychopharmacology 173: 425-33.

Curran HV, Travill RA (1997) Mood and cognitive effects of +/-3,4methylenedioxymethamphetamine (MDMA, 'ecstasy'): week-end 'high' followed by mid-week low. Addiction 92: 821-31.

Daumann J, Hensen G, Thimm B, Rezk M, Till B, Gouzoulis-Mayfrank E (2004) Selfreported psychopathological symptoms in recreational ecstasy (MDMA) users are mainly associated with regular cannabis use: further evidence from a combined cross-sectional/longitudinal investigation. Psychopharmacology 173: 398-404.

de Win MML, Reneman L, Jager G, Vlieger EP, Olabarriaga SD, Lavini C, Bisschops I, Majoie CB, Booij J, Den Heeten GJ, van den Brink W (2007) A prospective cohort study on sustained effects of low-dose ecstasy use on the brain in new ecstasy users. Neuropsychopharmacology 32: 458-470.

Dunn M, Degenhardt L, Campbell G, George J, Johnston J, Kinner S, Matthews A, Newman J, White N (2007) Australian trends in ecstasy and related drug markets 2006: findings from the ecstasy and related drugs reporting system (EDRS). National Drug and Alcohol Research Centre, UNSW, (NDARC Monograph No. 91). Sydney 
Durdle H, Lundahl LH, Johanson C, Tancer M (2008) Major depression: The relative contribution of gender, MDMA and cannabis use. Depression and Anxiety 25: 241247.

Falck RS, Wang J, Carlson RG (2008) Depressive symptomatology in young adults with a history of MDMA use: a longitudinal analysis. Psychopharmacology 22: 47-54.

George AM, Windsor TD, Rodgers B (2011) Ecstasy users are not biased toward endorsing somatic mental health symptoms: Results from a general community sample. Psychopharmacology 214: 901-909.

George J, Kinner SA, Bruno R, Degenhardt L, Dunn M (2010) Contextualising psychological distress among regular ecstasy users: the importance of sociodemographic factors and patterns of drug use. Drug And Alcohol Review 29: 243-249.

Goldberg D, Bridges K, Duncan-Jones P, Grayson D (1988) Detecting anxiety and depression in general medical settings. British Medical Journal 297: 897-899.

Guillot CJPD (2007) Is recreational ecstasy (MDMA) use associated with higher levels of depressive symptoms? Journal of Psychoactive Drugs 39: 31-39.

Hammersley R, Ditton J, Smith I, Short E (1999) Patterns of ecstasy use by drug users. British Journal of Criminology 39: 625-647.

Kwok O, Underhill AT, Berry JW, Luo W, Elliott TR, Yoon, M (2008) Analyzing Longitudinal Data with Multilevel Models: An Example with Individuals Living with Lower Extremity Intra-articular Fractures. Rehabilitation Psychology 53: 370386.

Lieb R, Schuetz CG, Pfister H, von Sydow K, Wittchen HU (2002) Mental disorders in ecstasy users: a prospective-longitudinal investigation. Drug and Alcohol Dependence 68: 195-207.

Martín-Santos R, Torrens M, Poudevida S, Langohr K, Cuyás E, Pacifici R, Farré M, Pichini S, De La Torre R (2010) GENETIC STUDY: 5-HTTLPR polymorphism, mood disorders and MDMA use in a 3-year follow-up study. Addiction Biology 15: $15-22$.

Medina KL, Shear PK (2007) Anxiety, depression and behavioral symptoms of executive dysfunction in ecstasy users: contributions of polydrug use. Drug and Alcohol Dependence 87: 303-311.

Miller P, Sønderlund A (2010) Using the internet to research hidden populations of illicit drug users: a review. Addiction Biology 105: 1557-1567.

Morgan MJ, McFie L, Fleetwood LH, Robinson JA (2002) Ecstasy (MDMA): are the psychological problems associated with its use reversed by prolonged abstinence? Psychopharmacology 159: 294-303.

Mueller M, Yuan J, McCann UD, Hatzidimitriou G, Ricaurte GA (2012) Single oral doses of ( \pm ) 3,4-methylenedioxymethamphetamine ('Ecstasy') produce lasting 
serotonergic deficits in non-human primates: relationship to plasma drug and metabolite concentrations. The International Journal of Neuropsychopharmacology FirstView: 1-11.

National Health and Medical Research Council (2001) Australian alcohol guidelines: Health risks and benefits. NHRMC, Canberra

Rogers G, Elston J, Garside R, Roome C, Taylor R, Younger P, Zawada A, Somerville M (2009) The harmful health effects of recreational ecstasy: a systematic review of observational evidence. Health Technology Assessment (Winchester, England) 13: iii.

Roiser JP, Sahakian BJ (2004) Relationship between ecstasy use and depression: a study controlling for poly-drug use. Psychopharmacology 173: 411-7.

Rosenman S, Rodgers B (2004) Childhood adversity in an Australian population. Social Psychiatry and Psychiatric Epidemiology 39: 695-702.

Saunders JB, Aaslanf OG, Babor TF, De La Fuente JR, Grant M (1993) Development of the Alcohol Use Disorders Identification Test (AUDIT): WHO collaborative project on early detection of persons with harmful alcohol consumption-II. Addiction 88: 791-804.

Schuster TL, Kessler RC, Aseltine RHJ (1990) Supportive interactions, negative interactions and depressed mood. American Journal of Community Psychology 18: 424-437.

Scott RM, Hides L, Allen JS, Burke R, Lubman DI (2010) Depressive and anxiety symptomatology in ecstasy users: the relative contribution of genes, trauma, life stress and drug use. Psychopharmacology 209: 25-36.

Singer JD,Willett JB (2003) Applied Longitudinal Data Analysis: Modeling Change and Event Occurrence. New York, Oxford University Press

Spitzer R, Kroenke K, Williams J (1999) Validation and utility of a self-report version of PRIME-MD: the PHQ primary care study. Primary care evaluation of mental disorders. Patient Health Questionnaire. JAMA 282: 1737-1744.

Sumnall HR, Cole JC (2005) Self-reported depressive symptomatology in community samples of polysubstance misusers who report ecstasy use: a meta-analysis. Journal of Psychopharmacology 19: 84-92.

Thomasius R, Zapletalova P, Petersen K, Buchert R, Andresen B, Wartberg L, Nebeling B, Schmoldt A (2006) Mood, cognition and serotonin transporter availability in current and former ecstasy (MDMA) users: the longitudinal perspective. Journal of Psychopharmacology 20: 211-225.

United Nations Office on Drugs and Crime (2012) World Drug Report. United Nations, New York 
World Health Organisation (1994) Composite International Diagnostic Interview (CIDI) Researcher's Manual. WHO, Geneva 
Table 1 Characteristics of the sample across the two waves

$\begin{array}{cr}\text { Wave } 2 & \text { Wave 3 } \\ \mathrm{N}=2,091-2,128^{\mathrm{a}} & \mathrm{N}=1,943-1,977^{\mathrm{a}}\end{array}$

Demographics

Male

$\%(\mathrm{~N})$

$47.4(1,008)$

$46.5(920)$

Highest education level

$\leq$ Higher school certificate $\quad \%(\mathrm{~N})$

$19.2(408)$

$14.0(272)$

Post-school qualification

$\%(\mathrm{~N})$

$36.7(780)$

$38.3(744)$

Tertiary educated

$\%(\mathrm{~N})$

$44.1(938)$

47.7 (927)

Married

$\%(\mathrm{~N})$

$26.4(561)$

45.6 (902)

Currently employed

$\%(\mathrm{~N})$

$88.6(1,885)$

$90.2(1,785)$

Financial problems in past

$\%(\mathrm{~N})$

$23.0(489)$

$18.6(367)$

year

Psychosocial variables

Total number of lifetime

$\mathrm{M}(\mathrm{SD})$

$1.33(1.44)$

$1.84(1.83)$

traumas

Number of adverse childhood

events (Wave 1 only)

$\mathrm{M}(\mathrm{SD})$

$1.54(2.11)$

Positive support from friends

$\mathrm{M}(\mathrm{SD})$

5.07 (1.20)

$5.06(1.19)$

Negative interaction with

$\mathrm{M}(\mathrm{SD})$

$2.98(1.74)$

$2.79(1.69)$

friends

Depression

Goldberg depression score $\quad$ M (SD)

$2.83(2.48)$

$2.63(2.44)$

Major/other depression (Brief

Patient Health Questionnaire)

Substance use variables

$\%(\mathrm{~N})$

$11.3(240)$

$9.4(185)$

Ecstasy use

$\begin{array}{lrrr}\text { Never used } & \%(\mathrm{~N}) & 68.6(1,459) & 64.2(1,269) \\ \text { Former use }^{\mathrm{b}} & \%(\mathrm{~N}) & 16.6(353) & 26.7(527) \\ \text { Infrequent use }^{\mathrm{c}} & \%(\mathrm{~N}) & 11.6(247) & 8.2(163) \\ \text { Use every month or more } & \%(\mathrm{~N}) & 3.2(69) & 0.9(18)\end{array}$


Meth/amphetamine use

$\begin{array}{lcrr}\text { Never used } & \%(\mathrm{~N}) & 73.7(1,569) & 73.1(1,446) \\ \text { Former use }^{\mathrm{b}} & \%(\mathrm{~N}) & 15.8(336) & 8.6(171) \\ \text { Infrequent use }^{\mathrm{c}} & \%(\mathrm{~N}) & 8.5(180) & -{ }^{\mathrm{d}} \\ \text { Use every month or more } & \%(\mathrm{~N}) & 2.0(42) & -{ }^{\mathrm{d}} \\ \text { Cannabis use } & & & 22.7(447) \\ \text { Never used } & \%(\mathrm{~N}) & 24.2(514) & 63.5(1,251) \\ \text { Former use }^{\mathrm{b}} & \%(\mathrm{~N}) & 52.7(1,118) & 7.9(156) \\ \text { Infrequent use }^{\mathrm{c}} & \%(\mathrm{~N}) & 13.4(285) & 5.8(115) \\ \text { Use every month or more } & \%(\mathrm{~N}) & 9.6(204) & 24.2(478) \\ \text { Hazardous/harmful drinker } & \%(\mathrm{~N}) & 28.3(603) & 20.9(413) \\ \text { Current smoker } & \%(\mathrm{~N}) & 27.4(583) & \end{array}$

${ }^{a}$ Sample sizes differ due to missing data for some variables.

${ }^{\mathrm{b}}$ Includes participants who have tried the substance, but not used in the past year and those who used the substance in the past year, but when asked how often they were currently using reported 'don't currently use'

${ }^{c}$ Refers to less than monthly use.

${ }^{\mathrm{d}}$ Data not presented since those who used meth/amphetamines and ecstasy, but no ecstasy in the prior 12 months were not asked questions regarding frequency of meth/amphetamine use at Wave 3. 
Table 2 Participant numbers at each wave by ecstasy status

\begin{tabular}{|c|c|c|c|c|}
\hline \multicolumn{5}{|c|}{ Wave 2} \\
\hline & $\begin{array}{c}\text { Ecstasy naive } \\
\mathrm{N}\end{array}$ & $\begin{array}{c}\text { Not using } \\
\quad \mathrm{N}\end{array}$ & $\begin{array}{c}\text { Currently using }{ }^{\mathrm{b}} \\
\mathrm{N}\end{array}$ & $\begin{array}{c}\text { Total } \\
\mathrm{N}\end{array}$ \\
\hline \multicolumn{5}{|l|}{ Wave 3} \\
\hline Ecstasy naive & 1,227 & na & na & 1,227 \\
\hline Not using ${ }^{\mathrm{a}}$ & 41 & 320 & 145 & 506 \\
\hline \multicolumn{5}{|l|}{ Currently } \\
\hline using $^{\mathrm{b}}$ & 10 & 34 & 133 & 177 \\
\hline Total & 1,278 & 354 & 278 & 1,910 \\
\hline
\end{tabular}

${ }^{\mathrm{a}}$ Includes participants who have tried ecstasy, but not used in the past year and those who used ecstasy in the past year, but when asked how often they were currently using reported 'don't currently use'.

${ }^{\mathrm{b}}$ Includes participants who have used ecstasy in the past year and when asked how often they were currently using the drug responded either every day, once a week, about once a month, every few months or once or twice a year/less often. 
Table 3 Multilevel modeling results: Estimates for predictors of change in Goldberg depression scale scores over 4 years $(\mathrm{N}=2,061)$

\begin{tabular}{|c|c|c|c|c|}
\hline $\begin{array}{c}\text { Model } 1 \\
\text { Beta (SE) }\end{array}$ & $\begin{array}{c}\text { Model } 2 \\
\text { Beta (SE) }\end{array}$ & $\begin{array}{c}\text { Model } 3 \\
\text { Beta (SE) }\end{array}$ & $\begin{array}{c}\text { Model } 4 \\
\text { Beta (SE) }\end{array}$ & $\begin{array}{c}\text { Model } 5 \\
\text { Beta (SE) }\end{array}$ \\
\hline$-0.14(.06)^{*}$ & $-0.15(.06)^{*}$ & $-0.04(.06)$ & $-0.14(.06)^{*}$ & $-0.11(.06)$ \\
\hline \multirow[t]{14}{*}{$0.30(.12)^{*}$} & $0.20(.14)$ & $0.24(.13)$ & $0.29(.13)^{*}$ & $0.19(.14)$ \\
\hline & $0.19(.11)$ & $0.11(.11)^{*}$ & $0.02(.10)$ & $-0.05(.12)$ \\
\hline & & $0.56(.09)^{*}$ & $0.80(.09)^{* * *}$ & $0.81(.09)^{* * *}$ \\
\hline & & $-0.19(.08)^{*}$ & $-0.10(.08)$ & $-0.07(.08)$ \\
\hline & & $1.02(.09)^{* * *}$ & $0.70(.09)^{* * *}$ & $0.67(.09)^{* * *}$ \\
\hline & & $-0.49(.12)^{* * *}$ & $-0.44(.12)^{* * *}$ & $-0.44(.12)^{* * *}$ \\
\hline & & $-0.25(.12)^{*}$ & $-0.26(.12)^{*}$ & $-0.24(.12)^{*}$ \\
\hline & & $-0.61(.13) * * *$ & $-0.48(.12)^{* * *}$ & $-0.40(.12)^{* * *}$ \\
\hline & & & $0.16(.03)^{* * *}$ & $0.14(.03)^{* * *}$ \\
\hline & & & $0.09(.02)^{* * *}$ & $0.09(.02)^{* * *}$ \\
\hline & & & $-0.38(.03)^{* * *}$ & $-0.38(.03)^{* * *}$ \\
\hline & & & $0.19(.02)^{* * *}$ & $0.18(.02)^{* * *}$ \\
\hline & & & & $0.37(.10)^{* * *}$ \\
\hline & & & & $0.13(.09)$ \\
\hline
\end{tabular}


${ }^{\mathrm{a}}$ Reference group is higher school certificate or less.

$* p \leq 0.05, * * p \leq 0.01, * * * p \leq .001$. 


\begin{tabular}{|c|c|c|c|c|c|}
\hline & Model 1 & Model 2 & Model 3 & Model 4 & Model 5 \\
\hline & OR $(95 \% \mathrm{CI})$ & OR $(95 \% \mathrm{CI})$ & OR $(95 \% \mathrm{CI})$ & OR $(95 \% \mathrm{CI})$ & OR $(95 \% \mathrm{CI})$ \\
\hline Time & $0.79(0.63-1.00)$ & $0.79(0.62-1.00)^{*}$ & $0.99(0.77-1.26)$ & $0.85(0.66-1.11)$ & $0.87(0.67-1.13)$ \\
\hline Current ecstasy use & $1.24(0.83-1.87)$ & $1.11(0.70-1.77)$ & $1.00(0.63-1.58)$ & $1.04(0.66-1.65)$ & $1.04(0.64-1.69)$ \\
\hline Ecstasy naive & & $1.18(0.83-1.66)$ & $0.96(0.69-1.35)$ & $0.89(0.64-1.24)$ & $0.90(0.61-1.33)$ \\
\hline Gender (female) & & & $0.94(0.71-1.25)$ & $1.34(1.00-1.79)$ & $1.38(1.03-1.85)^{*}$ \\
\hline Marital status (married) & & & $0.49(0.36-0.67)^{* * *}$ & $0.56(0.41-0.76)^{* * *}$ & $0.57(0.42-0.78) * * *$ \\
\hline Financial problems & & & $3.42(2.52-4.64)^{* * *}$ & $2.07(1.52-2.80)^{* * *}$ & $2.03(1.50-2.75)^{* * *}$ \\
\hline Employment status (employed) & & & $0.45(0.31-0.65)^{* * *}$ & $0.54(0.37-0.78)^{* *}$ & $0.56(0.39-0.82)^{* *}$ \\
\hline $\begin{array}{l}\text { Highest education level }^{\mathrm{a}} \\
\text { Post-school qualification } \\
\text { Tertiary educated }\end{array}$ & & & $\begin{array}{r}0.83(0.58-1.20) \\
0.52(0.35-0.76)^{* *}\end{array}$ & $\begin{array}{r}0.82(0.57-1.18) \\
0.63(0.43-0.93)^{*}\end{array}$ & $\begin{array}{r}0.84(0.58-1.20) \\
0.66(0.45-0.97)^{*}\end{array}$ \\
\hline Number of lifetime traumas & & & & $1.17(1.07-1.26)^{* * *}$ & $1.17(1.08-1.26)^{* * *}$ \\
\hline $\begin{array}{l}\text { Total number of childhood } \\
\text { adversities }\end{array}$ & & & & $1.06(0.99-1.12)$ & $1.05(0.99-1.12)$ \\
\hline Positive support from friends & & & & $0.59(0.53-0.65)^{* * *}$ & $0.59(0.53-0.65)^{* * *}$ \\
\hline Negative support from friends & & & & $1.19(1.10-1.28)^{* * *}$ & $1.17(1.09-1.26)^{* * *}$ \\
\hline Current smoker & & & & & $1.12(0.81-1.55)$ \\
\hline
\end{tabular}




\begin{tabular}{lcccc}
\hline & $\begin{array}{c}\text { Model 1 } \\
\text { OR (95\% CI) }\end{array}$ & $\begin{array}{c}\text { Model 2 } \\
\text { OR (95\% CI) }\end{array}$ & $\begin{array}{c}\text { Model 3 } \\
\text { OR (95\% CI) }\end{array}$ & $\begin{array}{c}\text { Model 4 } \\
\text { OR (95\% CI) }\end{array}$ \\
Hazardous/harmful alcohol use & & & & $1.06(0.77-1.45)$ \\
Current cannabis use & & & $1.17(0.79-1.71)$ \\
Ever used meth/amphetamines & & & $0.86(0.57-1.30)$ \\
\hline
\end{tabular}

${ }^{*} p \leq 0.05, * * p \leq 0.01, * * * p \leq .001$

${ }^{\mathrm{a}}$ Reference group is higher school certificate or less. 